\title{
DEVELOPING ALGeBRaIC PROBLEM POSING SKILLS of PROSPECTIVE TEACHERS USING GEOGEBRA ENVIRONMENT
}

\author{
Reda Abu Elwan,PhD \\ Sultan Qaboos University, \\ Muscat, Oman \\ abuelwan@squ.edu.om
}

Abstract 
The study was designed to support Prospective Mathematics Teachers (PMTs) on developing algebraic problem posing skills using GeoGebra environment. The Purpose of the study were to evaluate how PMTs develop new algebraic problems using GeoGebra, and to analyze how GeoGebra is a supported environment for these tasks. The sample of the study is composed of twenty PMTs in their final grade of College of Education, Sultan Qaboos University who were enrolled in "Methods of Teaching Mathematics" course on Fall 2012. The participants were administered problem posing tasks in Algebra which encompassed the topic of "Problem Solving and Applications of Algebra" as a part of the course. A learning environment with GeoGebra encouraged PMTs to propose new problems and confirm the forecasted through experiment. According to the results of the study, some of PMTs tended to perceive GeoGebra as not merely a tool but rather an environment for learning Algebra. They viewed GeoGebra as serving the purpose of supporting problem posing skills.

\section{INTRODUCTION}

Technology is becoming an increasingly important factor in everyday life and computers are available virtually everywhere particularly in developed countries. At the same time, educational organizations have started to develop technology-related standards (Lawless \& Pellegrino, 2007) trying to foster the integration of technology into teaching and learning. For example, the National Council of Teachers of Mathematics' (NCTM) Principles and Standards for School Mathematics dedicated technology as one of their six principles for school mathematics: "Technology is essential in teaching and learning mathematics; it influences the mathematics that is taught and enhances students' learning." (NCTM, 2000, p. 11). New learning opportunities are provided in technological environments, potentially engaging students of different mathematical skills and levels of understanding with mathematical tasks and activities 
(Hollebrands, 2007). The visualization and exploration of mathematical objects and concepts in multimedia environments can foster understanding in different ways; Van Voorst (1999, p.2) highlighted that technology was "useful in helping students view mathematics less passively, as a set of procedures, and more actively as reasoning, exploring, solving problems, generating new information, and asking new questions." Technological environments may also allow teachers to adapt their instruction and teaching methods more effectively to their students' needs (NCTM, 2000). In this study, the open-source software GeoGebra was selected from the pool of available software packages for mathematics teaching and learning (e.g., dynamic geometry software (DGS), computer algebra systems (CAS) and spreadsheets, because GeoGebra is a versatile tool that combines the ease of use of DGS with features of CAS. GeoGebra is freely downloadable from the Internet and thus it is available both in schools and at home without any limitations (Hohenwarter \& Lavicza, 2007). To date there is only limited research available in relation to the effective integration of GeoGebra into Problem Posing process (Bulut\& Bulut, 2011). The use of GeoGebra has been used to improve capability and success in teaching and learning environments. By integrating educational tools such as GeoGebra into teachers' everyday teaching practice, they can provide creative opportunities for supporting students' learning and fostering the acquisition of mathematical knowledge and skills. GeoGebra creates an atmosphere where the teacher encourages the students to think creatively and promotes a problem-oriented approach to the teaching of mathematics. GeoGebra has also great potential in the teaching of algebra which lies mainly in functions and graphs (Hohenwarter and others;2009).

In Shimizu (2008), he said "In European and American mathematical Education, teachers and government officials think not only of mathematical performance with paper and pencil but also with computers or other technology. They bring mathematical competency into view and then require 
further effort by requiring students to solve problems using technology", so students can solve problems by exploring mathematics through dynamic work.

In the recent technological environments, when the condition is changed in a problem by adding or removing in givens, we can simulate the influence of it and our conjecture is confirmed at once. Especially in multi-representative environments (tables, graphs, expressions, symbols and variables..). Teacher can approach the task in various ways; they showed students various ways for approach tasks by using GeoGebra. Then students tried to pose new graph situation for problems again and to reestablish new conditions of givens using GeoGebra. when students use GeoGebra, they can easily calculate difficult calculations. And they can see the dynamic changes in shape. Students can focus on thinking, not calculation. Through changes in graphs, symbols and numerals, it is possible for them to find mathematical laws and formulas.

\section{PROBLEM POSING IN MATHEMATICS}

"Problem posing and problem solving are obviously closely related. On the one hand, problem posing draws heavily on the processes of problem solving, such as identifying the key elements of a problem and how they relate to one another and to the goal of the problem. On the other hand, "problem posing takes children beyond the parameters of the solution process " (English, 1997, 173) it goes to think in the depth of problem structure, and different solutions. Problem posing instruction involves instruction with student's generation or formulation of problems to solve (Silver, 1994). It involves the creation of original problems which may be associated with some particular conditions. Problem posing in mathematics refers to cognitive activities: posing problems based on a given problem and posing problems based on a given situation or semi-given situation (Kilpatrick, 1987). Students who engage in problem posing activities become creative, enterprising and active learners. Studies show that problem posing might improve the 
students' attitudes toward mathematics and make them more responsible for their learning (Brown and Kenny, 1996; AbuElwan, 2002). It is important to develop mathematical problem posing skills for mathematics teachers. They (Teachers) are in need to develop mathematical problems which they present to their students. When students are solving textbook exercises they need to create new and different ideas based on these exercises, or they can formulate new mathematics problems from current situations relating to daily life. There are several strategies to enhance problem posing skills for students or teachers, (Kilpatrick, 1987; Silver, 1994) mentioned sources of problems: generation of problem based on a given problem, generation of problem based on a given context or a given calculation and problem posing based on a given situation. (Brown and Walter, 1993) suggested "what....if?" and "what....if not?" strategies where learner can think through problem givens and new questions of the new constructed problem. We can develop and create these strategies in algebraic problem posing in classes as well as we can develop that based on GeoGebra as learning environmental, where problems and problem posing could take place on the GeoGebra components. Using "What if?" and "What if not?" strategies in problem posing in developing new algebraic problems.

\section{GEOGEBRA ENVIRONMENT TO SUPPORT ALGEBRAIC PROBLEM POSING}

GeoGebra is a dynamic mathematics software for schools that joins geometry, algebra, and calculus, it is an interactive geometry system. Students could form an aspect by which they expressed a problem symbolically or made generalizations since they could change the value or move the point in a figure. With GeoGebra it is possible to create constructions with points, vectors, segments, lines, and conic sections as well as functions while changing them dynamically afterwards. The two characteristic views of GeoGebra are: an expression in the algebra window corresponds to an object in 
the geometry window and vice versa. GeoGebra user interface consists of a graphics window and an algebra window. On the one hand we can create geometric constructions on the drawing pad of the graphics window and, on the other hand, we can directly enter algebraic input, commands, and functions into the input field by using the keyboard. (Little,c.;2008) suggested that GeoGebra builds on the commercial packages such as "Geometers Sketch Pad" and "Cabri" by offering the user the interplay between geometry and algebra, he also believes the web based nature of GeoGebra enables many users (Prospective teachers) around the world to collaborate and share ideas on how to effectively use GeoGebra. Several features and functional tools of GeoGebra, such as hiding and then revealing strategies, as well as the bidirectional interaction of the drag mode are incorporated as a way of supporting "what if" strategy in problem posing. Students could develop a dynamic viewpoint with which they could move the figure under a given condition

To mediate GeoGebra in an interactive environment, it is important for PMTs to follow the mathematics step-by-step processes slowly; learning to engage and then achieve results, working alongside GeoGebra. Functions can be defined algebraically and then changed dynamically afterwards (Sangwin, 2007). For example, by entering the equation $y=x^{2}$ the corresponding graph can be seen directly. The visualization of two windows provides a connection between algebraic and geometric representations. It also works the other way around, by dragging the line or curve of the graph to change the equation. The change in the equation can be seen on the algebraic window.

For example; one of PMTs were asked to teach how do Geogebra support the idea of problem posing using "What..If?" strategy in quadratic functions to a class of microteaching situation as in the training session, he has the equation: $x^{2}+3 x-4=0$, the proposed problem was " The width of a rectangle box is three more than the width. The area 
is four square $\mathrm{cm}$. what are the dimensions of the box?", solution was going through $x(x+3)=4$, as shown in fig (1), then he moved the curve to form a new equation using "what..if" as what if I moved the curve to represent the equation: $3 x^{2}-3 x-6=0$, he developed a new problem based on the new equation " the area of a square is two more than square side length, what is a square side length?", solution was going through $x^{2}=x+2$, as shown in fig (2).

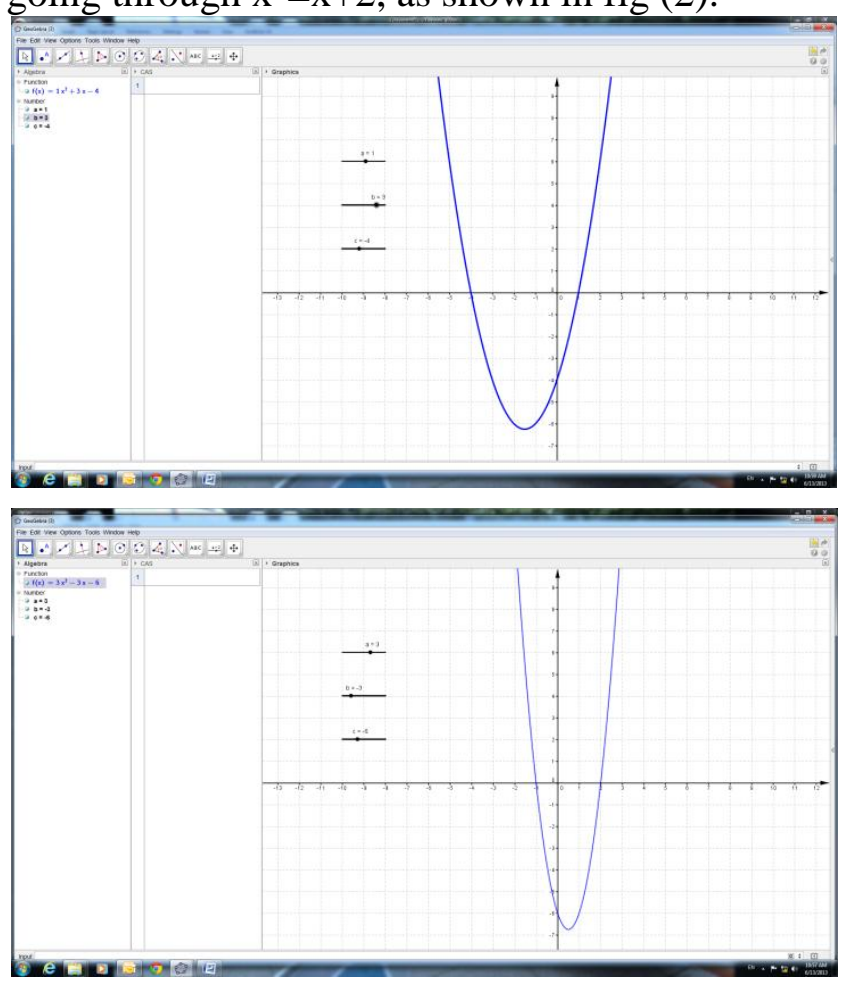

Fig.1

Fig. 2

Chris Sangwin illuminates the way GeoGebra behaves both "geometrically and algebraically" Sangwin suggests: "This mixing of algebra and geometry is the heart of GeoGebra". Summing up his demonstration of the logistic map Chris Sangwin said (Sangwin ,2007;37) "The effectiveness of this needs to be experienced, and is certainly visually more appealing than a sequence of static pictures such as might be provided in a book". In developing my Methods course for 
PMTs, I did integrate GeoGebra v. 4.2 as a new dynamic environment in the course, so PMTs can use it to support the topic of "Problem Posing strategies in Algebra".

\section{Objectives and Research Questions}

The purposes of this study were to show increase retention of posing new algebraic problems and success with technology supported education. In other words the purposes of this study were to evaluate how PMTs develop new Algebraic problems using GeoGebra, and to analyze how does GeoGebra be a supported environment for these tasks.

Research questions of this study are:

1. Does experience with GeoGebra environment enhance MPTs' skills to formulate new Algebraic problems?

2. What are MPTs' opinions about GeoGebra as an effectiveness environment in Algebraic Problem Posing?

\section{Instruments}

- To investigate MPTs of using GeoGebra environment in problem posing, the researcher used "Task Analysis" as a tool for that purpose; it showed how dose participants could construct a new Algebraic problem and what kind of formulated problem they are developed, and what they can do to modify ill formulated problem?

- To investigate MPTs' opinions about using GeoGebra environment in problem posing, I used "Opinions Questionnaire" with each participant, asking them about their opinions about GeoGebra environment in Problem posing.

\section{METHODS}

\section{Subjects and contexts}

The subjects involved in this study were 20 student-teachers enrolled in "methods of teaching mathematics" course presented in association of "Teaching Practice training field", each two student-teachers working together to create new algebraic problem based on: PMTs' knowledge of algebraic 
quadratic functions as a part of Problem Solving and Applications of Algebra unit, their skills of using GeoGebra software utilities, and problem posing strategies. Working in cooperative groups allows students to check their results with other group members. After the students finished their individual tasks, they can collect data about solutions they achieved and use these data to make conjectures and test them in their group before presenting their new problem and solutions to the whole class.

Several workshops in using GeoGebra (www.geoGebra.org) was important to introduce facilities of GeoGebra software, algebraic problem solving, and algebraic problem posing were presented to PMTs using their Laptops, in four weeks, 3hours a week. The designed workshops in this study were designed to introduce GeoGebra to novice users. Furthermore, workshops highlighted additional opportunities that GeoGebra can offer in posing new dynamic environments. Hence, workshops allowed the introduction of problems from algebra.

Although these workshops were tailored for PMTs in Oman, their design was based on experiences gathered from other experiences previously held in different mathematics courses. As a routine, workshops began with discussing homework exercises followed by activities designed to enable participants' to work independency using GeoGebra. After every workshop the PMTs were required to complete a short homework exercise. The content of the workshops was selected from "Problem Solving and Applications of Algebra" unit. Topics ranged from using equations as models, through experimenting with linear equations, to solving functions in GeoGebra. Consequently, the participants were introduced to GeoGebra's tools and the "drag test" which allow participants to dynamically modify constructions and explore their correctness. 
Initially, the teacher's role was to explain how to construct algebraic functions. Problem Solving and Applications of Algebra topics taught in 3 hours in one workshop for three workshops. All teaching and training was conducted by the researcher. The phase of constructing new algebraic problems using GeoGebra was done at the final stage of the course. They stimulate pupils' algorithmically thinking and they can be a basis for beginning programming activities as well. All these problems involve MPTs actively in the phase of the construction of the algebraic problems, allowing them to invent new ones by themselves. So, I gave the MPTs the task of posing problem and solving own posed problem. It gave MPTs change their viewpoints in an algebraic problem. Accepted algebraic problem criteria were: Using GeoGebra environment, context of the formulated problem should be related to Problem Solving and Applications of Algebra topic, and new generated problems are solvable. Through the methods course, PMTs learn to orchestrate a learning environment by developing strategies for gaining and maintaining algebraic Problem posing skills and for conducting GeoGebra learning activities so that they are willingly and enthusiastically engage in problem posing skills.

\section{RESULTS AND DISCUSSION}

At the final stage of training where GeoGebra was used in problem posing, all participants were asked to use GeoGebra to formulate two different problems; one problem was based on "What if" strategy, while the other was designed based on "what if not" strategy. The proposed problem was to use the same context.

Data were collected as the participants constructed problems and as they described the way in which these problems were developed. A total of 40 new Algebraic problems were posed by the twenty participants. The new posed problems were classified as shown in table 1.

\begin{tabular}{|c|c|c|c|}
\hline $\begin{array}{c}\text { Strategies used in posed } \\
\text { problems }\end{array}$ & "What if?" & "What if not?" & total \\
\hline Number of posed problems & 25 & 15 & 40 \\
\hline
\end{tabular}




\section{Table 1: Number of new posed problems}

While table 1 showed that PMTs were interested to use "What if" strategy" more than "what if not" strategy as they found that "what if" strategy needed to add some givens to the original problem, so it is much easier when they use GeoGebra to modify the original problem. All constructed problems were analyzed based on criteria of algebraic problem posing mentioned early. PMTs faces difficulties in using "what if not?" strategy in formulating extended problems, because of the data they have to remove in order to rebuild a suitable well constructed problems.

In order to measure PMTs beliefs on using GeoGebra in Algebraic Problem Posing, a designed Opinions Questionnaire has been developed by the author consists of ten questions for PMTs chosen for their importance for using GeoGebra in Algebraic problem posing and their effectiveness in teaching and learning algebra. Items of questions were written in a clear statements that reflect their first uses of GeoGebra in a cognitive task which is Problem posing.

At the end of, the final GeoGebra training session, a questionnaire with a five scale points; 1 point was specified as the lowest score, 5 point was specified as the highest point. was given to PMTs.

\begin{tabular}{|l|l|l|l|l|l|l|l|l|l|l|l|}
\hline$\#$ & Questions & $\mathbf{1}$ & $\mathbf{\%}$ & $\mathbf{2}$ & $\mathbf{\%}$ & $\mathbf{3}$ & $\mathbf{\%}$ & $\mathbf{4}$ & $\mathbf{\%}$ & $\mathbf{5}$ & $\mathbf{\%}$ \\
\hline 1 & $\begin{array}{l}\text { According to } \\
\text { your first } \\
\text { impression, do } \\
\text { you think that } \\
\text { GeoGebra is } \\
\text { useful for you? }\end{array}$ & 0 & 0 & 0 & 0 & 5 & 25 & 9 & 45 & 6 & 30 \\
\hline 2 & $\begin{array}{l}\text { Do you think } \\
\text { that, GeoGebra } \\
\text { provides } \\
\text { opportunities to } \\
\text { pose algebraic } \\
\text { problems? }\end{array}$ & 0 & 0 & 2 & 10 & 11 & 55 & 4 & 20 & 3 & 15 \\
\hline 3 & $\begin{array}{l}\text { Do you think } \\
\text { that, GeoGebra is } \\
\text { an effective } \\
\text { environment in }\end{array}$ & 0 & 0 & 0 & 0 & 2 & 10 & 12 & 60 & 6 & 30 \\
\hline
\end{tabular}




\begin{tabular}{|c|c|c|c|c|c|c|c|c|c|c|c|}
\hline & Problem Posing? & & & & & & & & & & \\
\hline 4 & $\begin{array}{l}\text { Do you think } \\
\text { that, GeoGebra is } \\
\text { that software that } \\
\text { gives you all } \\
\text { possibilities in } \\
\text { Algebraic } \\
\text { problem posing? }\end{array}$ & 0 & 0 & 3 & 15 & 8 & 40 & 6 & 30 & 3 & 15 \\
\hline 5 & $\begin{array}{l}\text { Do you think } \\
\text { that, GeoGebra } \\
\text { can overcome the } \\
\text { difficulties on } \\
\text { Using Problem } \\
\text { Posing } \\
\text { Strategies? }\end{array}$ & 0 & 0 & 0 & 0 & 1 & 5 & 14 & 70 & 5 & 25 \\
\hline 6 & $\begin{array}{l}\text { Do you think } \\
\text { that, GeoGebra } \\
\text { can make } \\
\text { Algebra and } \\
\text { calculus } \\
\text { enjoyable? }\end{array}$ & 1 & 5 & 1 & 5 & 3 & 15 & 5 & 25 & 10 & 50 \\
\hline 7 & $\begin{array}{l}\text { Do you think } \\
\text { that, GeoGebra is } \\
\text { used for all } \\
\text { Algebraic } \\
\text { Problems? }\end{array}$ & 2 & 10 & 3 & 15 & 7 & 35 & 5 & 25 & 3 & 15 \\
\hline 8 & $\begin{array}{l}\text { Do you think } \\
\text { that, GeoGebra is } \\
\text { used in Algebraic } \\
\text { Problem Posing } \\
\text { under specific } \\
\text { conditions? }\end{array}$ & 0 & 0 & 0 & 0 & 0 & 0 & 6 & 30 & 14 & 70 \\
\hline 9 & $\begin{array}{l}\text { Do you think } \\
\text { that, Algebraic } \\
\text { Problem Posing } \\
\text { is an important } \\
\text { for you as a } \\
\text { Prospective Math } \\
\text { Teachers? }\end{array}$ & 0 & 0 & 0 & 0 & 4 & 20 & 6 & 30 & 10 & 50 \\
\hline 10 & $\begin{array}{l}\text { Do you think } \\
\text { that, GeoGebra is } \\
\text { used in Algebraic } \\
\text { Problem Solving } \\
\text { Effectively? }\end{array}$ & 0 & 0 & 0 & 0 & 5 & 25 & 8 & 40 & 7 & 35 \\
\hline
\end{tabular}

Table 2: Participants Responses to Questionnaire

Table 2 illustrates the participants' answers and their percentage scores about GeoGebra. When the data of Table1 were analyzed, GeoGebra was preferred for better success by 
PMTs. Results showed that PMTs believed that GeoGebra is an effective environment for problem posing as it is showed in questions 3, 4 and 5. While they believes that GeoGebra should be used under some conditions when it used for problem posing as in question 8. Although that after the first session the PMTs' view on enjoyment from working with GeoGebra was largely positive. The participants' initial impressions that GeoGebra could help with algebraic problem posing were strengthened and the view that it was easy to use held firm. Nevertheless, some of participants finding it not easy to use are significant.

GeoGebra environment provides a perfect link between mathematical textbooks and technology and a very comfortable and desired environment for problem-solving situations and problem posing tasks through research work. All the described features of GeoGebra, this new technology itself, confirm this aspect.

\section{REFERENCES}

Abu-Elwan, R. (2002). Effectiveness of Problem Posing Strategies on Prospective Mathematics Teachers' Problem Solving Performance, Journal of Science and Mathematics Education in Southeast Asia, 25(1),pp. 56-69.

Brown, S.and Walter, M. (1993). Problem Posing in Mathematics Education. In Brown S. and Walter M. (Eds.) Problem Posing: Reflections and Applications, Hillsdale, NJ; Erlbaum. pp. 16-27.

Bulut, M. And Bulut, N. (2011). Pre Service Teachers' Usage of Dynamic Mathematics Software. TOJET, V.10, N.4.

English, Lyne D. (1997). Promoting a Problem Posing Classroom, Teaching Children Mathematics, November, p.173 
Hohenwarter, M. and Lavicza, Z. (2007) Mathematics Teacher Development with ICT: Towards an International GeoGebra Institute, in D. Küchemann (Ed.) Proceedings of the British Society for Research into Learning Mathematics, 27 (3), 4954.

Hohenwarter,J., Hohewarter, M.\& Laviczaz. (2009). Introducing Dynamic Mathematics Software to Secondary School Teachers: The case of GeoGebra. Journal of Computers and Mathematics and Science Technology, 28(2), 135-146.

Hollebrands, K. F. (2007). The role of a dynamic software program for geometry in the strategies high school mathematics students employ. Journal for Research in Mathematics Education, 38(2):164192.

Kilpatrick, J. (1987). Problem Formulating: Where Good Problems Come from? In A.H. Schoenfeld (Ed.), Cognitive Science and Mathematics Education pp. 123-147. Hillsdate, NJ. Erlbaum.

Lawless A.\& Pellegrino W.(2007). Professional Development in Integrating Technology into Teaching and Learning: Knowns, Unknowns and Ways to Pursue Better Questions and Answers. Review of Educational Research, Dec. 2007, Vol. 77, N. 4

Little, C. (2008), Interactive geometry in the classroom: old barriers and new opportunities, Proceedings of the British Society for Research into Learning Mathematics 28(2) MEI Use of ICT Online retrieved May 21st 2012 from http://www.mei.org.uk/files/ict/m1ja07_geogebra.z ip

NCTM (2000). Principles and Standards for School Mathematics. National Council of Teachers of Mathematics. 
Sangwin, C, (2007) A brief review of GeoGebra: dynamic mathematics, MSOR Connections Vol 7 No 2 May - July 2007, pages 36-38

Shimizu, K. (2008). An Importance of Computer Enhanced Problem Solving Ability in Mathematics and Information Education. Proceeding of $32^{\text {nd }}$ conference of Japan Society for Science Education.

Silver,E. A. (1994). On mathematical problem posing. For the learning of mathematics. 14 (1), pp 19-28.

Van Voorst, C. (1999). Technology in mathematics teacher education. Retrieved November

12, 2012, from http://www.icte.org/T99 Library/T99 54.PDF. 